\title{
USE OF CLOUD COMPUTING AND ACCOUNTING: BUSSINESS PRESPECTIVE
}

\author{
Author \\ PROF. (DR.) GURUDUTTA P. JAPEE \\ S.D SCHOOL OF COMMERCE, \\ GUJARAT UNIVERSITY, NAVRANGPURA, \\ AHMEDABAD \\ Co-Author \\ ANKIT JOSHI \\ RESEARCH SCHOLAR \\ S.D. SCHOOL OF COMMERCE AHMEDABAD \\ GUJARAT UNIVERSITY
}

\begin{abstract}
Now a day's business houses started adopting and currently are using cloud computing and accounting Because of growth possibilities or potential of cloud computing and accounting as a world scenario. Business houses developed their own big data centers, private cloud or hybrid cloud as a support for their processes within the shared virtual and configurable resource. Cloud computing and accounting technology process and store a series of sensitive and confidential data (financial statements, financial reports, A.O.A and M.O.A) of a business houses. Cloud accounting and computing technology adoption provides a rigorous analysis of data and application security. In this paper which is based on a descriptive analysis of existing literature and specialized practice in this field. We wish to synthesize the potential of cloud accounting and computing in the development of business houses.
\end{abstract}

\section{INTRODUCTION}

Business houses are formed for the purpose of profit making and thus they are carried out some economical activity. Increase profit on a continuous scale and now a day's cost cutting is also important for survival in a cut through competition. Cloud computing provides numerous benefits to a business house which are the key factors for the development of business house. Usage of Cloud accounting and computing provides a major impact on Accounting Information Systems within organizations. The software as a services approach has a significant and direct impact on the company's financial and accounting processes. Cloud accounting and computing significantly impacts the business strategies of companies, the way companies do business and define the hardware, software and communication infrastructures, risk management and cost management. Cloud computing technology provides various business models for solving business problems to business just like Software-as-a-Service (SaaS), Infrastructure-as-a-Service (IaaS), Platform-as-a-Service (PaaS), Business Process-as-a-Service (BPaaS), and data base as a service. Automatic Documents Entry, Mobile Customer Service, and Mobile Accounting Service are all those features are provided in this service. Multiple implications of cloud computing and accounting on today's business process, which we briefly describe in this research regarding on how these technologies can be used in Accounting Information Systems (AIS) in order to improve the accuracy, completeness, and timeless of accounting information. 


\section{CLOUD COMPUTING AND ACCOUNTING DEFINITION}

A common definition is given in a NIST report; "Cloud computing is a model for enabling ubiquitous, convenient, on demand network access to a shared pool of configurable computing resources (e.g., networks, servers, storage, applications, and services) that can be rapidly provisioned and released with minimal management effort or service provider interaction".

Cloud accounting is a terminology in which all the economic transaction like recording, classifying, summarizing, analyzing and presenting with the integration of cloud computing technology with the configurable resource and virtual resource.

\section{Characteristics of Cloud Computing\& accounting}

$>$ On-demand self-service: all the resource is or data are stored in cloud by client itself and access by client itself here there is no requirement of permission of any third party. It is on demanded services of client.

$>$ Broad network access: in this platform unlimited data is to be stored and network which access configurable resource is from broad network.

$>$ Resource pooling: in cloud computing and accounting unlimited data is to be stored and resource are pooled at a large scale basis and access from anywhere with network access.

$>$ Rapid elasticity: it is a more elastic and provides more flexibility in terms of billing, quality and resource allocation to the client.

$>$ Measured service: service of cloud service provider is measured in terms of scale which is decided in terms of agreement.

\section{REVIEW OF LITERATURE}

Gupta et al. (2013) study suggested that there are various solutions which cloud computing services provides as features to a business entity and also all those factors which is a key in for adopting cloud computing services these are ease of use, security, cost reduction, reliability and sharing and collaboration.

Cloud computing and accounting services refer to either or a combination of the following.

- IT Infrastructure as a service (IaaS)

Infrastructure service provider, provide physical storage space, processing capabilities, virtual CPUs and database services to client.

- Platform as a service (PaaS)

A package of software and product development tools for development, testing, deployment, hosting and application maintenance hosted on the provider's infrastructure. Cloud service provider (Software developers) can create applications on the provider's platform through the Internet.

- Software as a service (SaaS)

The end-user (business houses) pays the software provider a cloud billing (subscription fee) for the service and the software is hosted openly from the software providers' servers and is access by the business through the Internet

Irshad et al. (2017) study reveals to understand the level of awareness and adoption of cloud computing and accounting by the academic staff in Sri Lankan universities. This study is conducted for the purpose of investigating the level of awareness of cloud accounting and computing technology and to what extent this technology is use by academic staff in Sri Lankan universities, and the reasons for adoption and non-adoption. One-third of the sample respondents are aware about the cloud computing and accounting technology.

The level of adoption by academic staff in Sri Lankan universities is limited to several applications, only up to Google Apps Engine and Drop box. Cost and time saving were stated as the reasons for adoption and the lack of benefits and security concerns were stated as the most important drivers for non-adoption by academic staff in Sri Lankan universities.

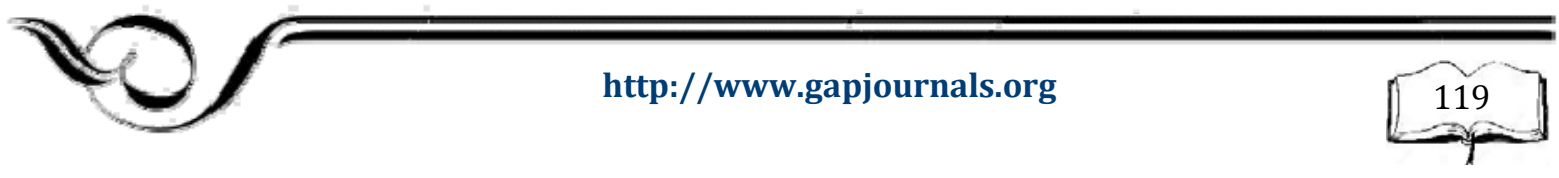




\section{GAP GYAN-

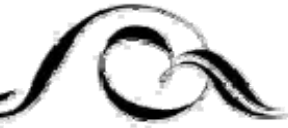

$78.4 \%$ of the respondents are aware of cloud computing, but only $14 \%$ respondent confirmed they have deeply knowledgeable about cloud computing and accounting.

Bagish (2014) Cloud accounting and computing is a latest technology and new trends. Cloud computing and accounting technology through software applications are running as a service over the internet on scalable infrastructure. Universities can take advantage of cloud computing and accounting technology through software application model to provide students and teachers with free or low cost tools. This paper aim to investigate the awareness of cloud computing and accounting among student and how often they use cloud computing and accounting technology. This study also aims to find out the student's opinion of using cloud computing collaboration application and the university administrator support to integrate and familiar to the student about cloud computing and accounting technology. Therefore the finding recommends that education and sensitization on cloud computing in order to increase awareness and knowledge about this cloud computing and accounting technology and its prospects to the student.

\section{Implication that are attached with cloud accounting and computing}

- Big Data storing: in cloud computing technology data storing features are available as you want. Data are stored on virtual platform and it is to be stored as rent space from cloud services provider and pay only that use from anywhere with configurable resource (internet). Business houses stored data through rent space on cloud from service provider

- Big data Manage\& control: cloud service provider maintains data which is provided by client and it is depends on space that was rented by client. Cloud services provider maintains big that which is very difficult to manage by institution because lack of resource.

- Manage E-content: today's online business houses are hub of E- content and management of all the resource are very difficult. It is very difficult to maintain E- content in proper management and useful for people when they required so that problems are solve by cloud computing service through cloud services provider. Management of E- content are provided by cloud agent in very cheap cost.

- Safe from uncertainties: many a time's possibility is there that data will be cruse and corrupt by virus and other uncertainties (fire at place). There are many problems associated with Data and due to this data is destroyed. All the resource is destroyed from uncertainties then cloud services provide backup service to their client according to their requirement. Cloud services provide safe service of data from uncertainties

- Back up service: cloud computing service provides back of data that was stored in cloud and according to their requirement without any extra cost of their resource. It provides numerous benefits like safety from circumstances.

- Automatic update: cloud services provider is also provide automatic update to their client according to available resource.

- Low cost: cloud services are provides all those services with low cost because pay what you use and big things that save from costly infrastructure that is necessary for data services and all those above services.

- Safe security of data from contingencies means cloud accounting and computing provides safe security of data to users.

- Real time information means provide real time information to various stakeholder.

- Flexibility means that flexibility in terms of contract, quality and payment etc.

- Pay according to their use means pay what you consume

- Physical existence is not important means physical important of accountant is not important from anywhere he perform respective task.

- Speed up transaction means that transaction is speeded by using new trends that is cloud accounting.

- Save energy means accountant with less effort work will perform by using it. 


\section{GAP GYAN-

- Save time means it reduces times in comparison to old traditional accounting.

- Easy for auditing purpose by using cloud computing and accounting technology.

- No hidden charges by cloud services provider.

- Capital expenditure converted into revenue expenditure.

- Back up service to the client whenever needed.

\section{Risk associated with cloud accounting and computing}

- Data migration by service provider: in many case it is seen that service provider are very selfish and they use data of client for money making and take undue advantage from data handling because ultimate handling in the hand of service provider because data is to be stored on remote server which is controlled in the hand of service provider

- Highly costly for big data: in most of the case cloud service provider are charge according to the use of resource or stored capacity and it is quite difficult to big data handling institution because big data require huge space and capacity so charge is very in terms of total amount because it is rented capacity and huge resource are applicable. It is very costly in comparison to that option about build infrastructure is less costly.

- Leakage of sensitive data: many times it is seen that cloud service provider are leak information or data which is very important and very sensitive for his personal interest and its loss the trust ship between client and cloud provider.

- Lack of legal provision: in this field contract of cloud computing between cloud service provider and client are not regulated by any controlled authority and it is quite difficult when dispute arise, so in this field strict rules and regulation are to be implement by govt.

- Poor quality service: Some of the cloud service providers are very cheap and they do not provide service according to standard. It provides poor quality of service to their client and not to solve any problems regarding it. So problems arise between cloud service provider and client.

- Internet access is necessary

- Confidentiality is not maintain

- Service is depended on service provider

- Additional cost or hidden charge

- It requires knowledge of computer science

- Illegal outsourcing

\section{CONCLUSION:}

Study conclude that there are numerous benefits that are associated with cloud accounting and computing to business world, by using cloud accounting and computing business is achieving new highest in modern arena. By adopting cloud computing and accounting, provides real time information to its various stakeholder like easy access of financial statement and report with internet access from anywhere to shareholder and management, customer satisfaction and problems solution of their customer on time with cloud computing and accounting. Data which is stored on cloud is safely stored on it and uncertainties cannot affect data and also back up service of data are available to client.

\section{REFERENCING}

T. Mell, "The NIST Definition of Cloud Computing," National Institute of Standards and Technology, Information Technology Laboratory, 2009

Gupta, P., Seetharaman, A., Raj, JR., 2013. The Usage and Adoption of Cloud Computing by Small and Medium Businesses, International Journal of Information Management, No.33, and pp. 861-874.

Irshad, M. B. M., Md. Gapar Md. Johar., 2017. The Study on Awareness and Adoption of Cloud Computing by Academics in Sri Lankan Universities, International Journal of Advanced Research in Computer Science and Software Engineering, Volume 7, Issue 5, pp.6-10

Bagish, Samah Sadeq Ahmed., 2014. Student's Awareness of Cloud Computing: Case Study Faculty of Engineering at Aden University, Yemen, IJEDR, Volume 2, Issue 1,pp. 1122-1129 